\title{
DETERMINATION OF ELEMENTAL COMPOSITION OF AIR PARTICULATES AND SOILS IN KHARTOUM AREA
}

\author{
FI Habbani, EM Eltahir and AS Ibrahim \\ Department of Physics, Faculty of Science \\ University of Khartoum, Khartoum, P. O. Box 321, Sudan
}

\begin{abstract}
Investigations were carried out for elemental composition of air particulates in the background air and near roadsides in Khartoum area. Investigations were also performed for the elemental composition of soils at the same locations. A cyclone and a dichotomous virtual impactor were used to measure the air particulates. The cyclone was adjusted to collect particles having an aerodynamic diameter of $2.5 \mu \mathrm{m}$. The virtual impactor, through its fine channel, was capable of collecting airborne particles with an aerodynamic diameter of $2.5 \mu \mathrm{m}$. Energy Dispersive X-Ray Fluorescence (EDXRF) analysis was used to study the elemental concentrations of the air and soil samples. The analysis of the results indicated that all elements in the proximity of roadsides have elevated concentrations compared to the background air levels. Enrichment factors were calculated relative to crust rock and Khartoum soil. The results showed that the elements $K, C a$, $\mathrm{Ti}, \mathrm{Fe}$, and $\mathrm{Sr}$ in the aerosols have their origin from the soil, while the elements $\mathrm{Zn}, \mathrm{Ni}$ and $\mathrm{Pb}$ have their source from automobile emissions. The results also indicated a correlation between lead and bromine. The lead to bromine ratio was found to be within the range of those derived from vehicular exhaust, and in good agreement with the ratios obtained from some other countries.
\end{abstract}

\section{INTRODUCTION}

Urban air particulates, which originate from various sources such as energy consumption and emissions from the transportation sector, are of concern because of their health effects. Air quality standards for particulate matter (PM) have been established in many countries based on PM10, a size-specific standard. PM10 is defined as the fraction of PM captured with $50 \%$ efficiency at $10 \mu \mathrm{m}$, and greater efficiency at smaller sizes. It has been shown in many studies that the elevated levels of PM10 are linked to increased adverse health effects. Particulate matter having diameter $2.5 \mu \mathrm{m}$ and below, referred to as PM2.5, is a sub-size of PM10. It is captured with $50 \%$ efficiency at 2.5 $\mu \mathrm{m}$. It can penetrate more deeply in the breathing system and can have serious health effects as well (Hinds 1982, Wahlin et al. 2001, McLellan 2002).

A major source of urban air particulates is emission from vehicular traffic which has been considerably increasing in the past decades. Other particulates may have their origin in the soil particles that build up through the process of soil re-suspension or mobilization.

Two mechanisms account for the traffic contribution to the roadsides airborne particulates. Re-suspension or mobilization of the soil particles by traffic has the larger part of the total mass of street dust, especially when roads are unpaved. The other mechanism is the direct emission from vehicles. To investigate the influences of the two sources on the roadside air particulates, the Enrichment Factors (EF) for some elements were calculated. This is needed to characterize whether the measured concentrations are originating from the soil re-suspension or are enhanced by automobile emissions. $\mathrm{Ti}$ and rock of crust material have been commonly used in calculations of EFs (Djupstrom 1995, Chimidza et al. 2001).

Crust rock was used as reference material for 
the calculations of the EFs for Khartoum aerosols. This is because Khartoum area lies in the southern belt of the Sahara desert and, it is thus expected to be influenced by Sahara soil particulates.

The EFs have been calculated using the relation:

$\mathrm{EF}(\mathrm{x})=\left(\mathrm{C}_{\mathrm{x}}(\mathrm{a}) / \mathrm{Ti}(\mathrm{a})\right) /\left(\mathrm{C}_{\mathrm{x}}(\mathrm{ref}) / \mathrm{Ti}(\mathrm{ref})\right)$

where $\mathrm{EF}(\mathrm{x})=$ enrichment factor for the element $\mathrm{x}$

$C_{x}(a)=$ concentration of the element $x$ in the measured aerosols

$\mathrm{Ti}$ (a) = concentration of $\mathrm{Ti}$ in the measured aerosols

$\mathrm{C}_{\mathrm{x}}(\mathrm{ref})=$ concentration of the element $\mathrm{x}$ in the reference material

$\mathrm{Ti}$ (ref) = concentration of $\mathrm{Ti}$ in the reference material

Impactors and cyclones are instruments widely used for separating particles over a desired diameter range. In the virtual impactor used in this study, the airborne matter is passed through a nozzle and then forced to bend abruptly at $90^{\circ}$ by an impaction surface. Particulates having high inertia will be collected through the impaction plate. Particles with low inertia will follow the stream of the air and will be collected on a different medium. A cyclone removes particles larger than a desired size range from the drawn air by means of centrifugal forces. The cut-off of the cyclone changes with different flow rates. The flow rate could be adjusted to get different cut-off diameters of particles by using limiting orifices. Particles with higher inertia are collected on the inner walls of the cyclone and eventually fall down to a grid pot, while particles with aerodynamic diameters smaller than the cut-off size follow the air stream (Hinds 1982).

EDXRF, which was used in this study, has been used widely as trace analytical technique for the environmental samples. It is known to be a non-destructive analytical technique, with multi-element capability and simple sample preparation. Analysis of heavy elements in aerosols by EDXRF is performed by measurement of a collection of the particulates on filters when a definite volume of air has been passed through the filters (Eltayeb 1993).

The possible sources of particulate matter in Khartoum area are the pollutants generated from the anthropogenic sources and human activities, such as vehicle emission, biomass burning and the growing industry (textile, cement, petroleum refining, tanning, electricity production, etc.). In addition to the anthropogenic air particulates, the wind blown dust from Sahara desert located in the north part of Sudan_was expected to exert some influence on the composition of air particulates in Khartoum area.

Some previous studies have been performed for particulate pollutants and vehicle traffic emissions in Khartoum area (Hassan 1984, Eltayeb 1993, Hassuna et al. 1998). In the study by Hassuna et a $l$. (1998), measurements were carried out for elemental concentrations in Khartoum aerosols, but the study did not segregate particles. Also the study lacked information on concentrations of the important element $\mathrm{Pb}$. The present study aimed to identify the sizes and the possible sources, as well as to determine the concentrations of the different elements in the airborne particles in Khartoum area. This was considered a fundamental step in the control of their presence and hazards. Some investigations were also made for $\mathrm{Pb}$ concentrations in soils near some road-sides in Khartoum city.

\section{MATERIALS AND METHODS} Selected locations

In this study airborne particulates were sampled at ten different locations near roadsides in the center of Khartoum. Another site inside the central campus of the University of Khartoum was selected to represent the general background air of the city. The ten locations near the roadsides were selected to represent the high traffic density roads near the different types of 
activities, commercial as well as residential. To investigate accumulation of atmospheric lead concentrations as a historical marker for automobile emissions, soil samples were taken from different distances and depths near the road-sides. Fig. 1 shows the selected locations for aerosols and soil samples.

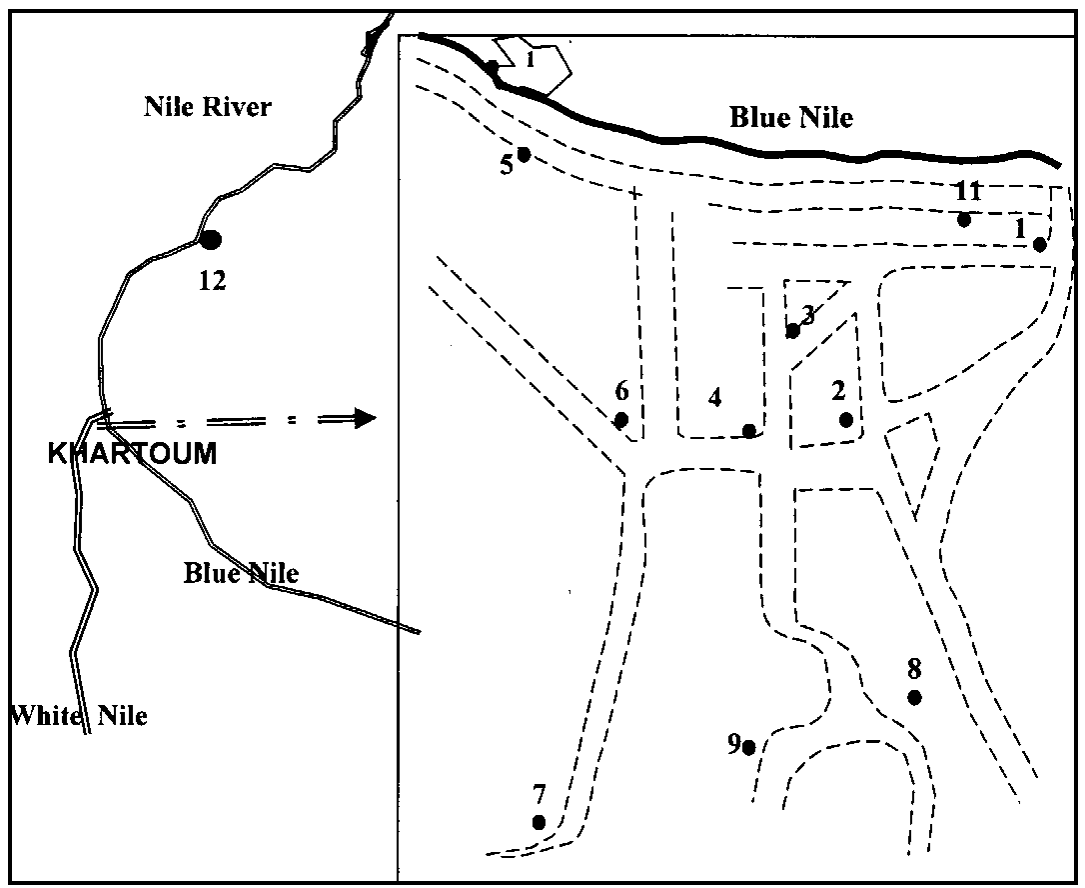

Figure 1: Locations of the atmospheric and soil samples in Khartoum area (1 Gamaa St, 2 Mack Nimir St 3 Atbara St 4 Gasr St 5. Nile St 6 Hurria St 7 Hurria St 8 Amarat St 9 Sahafa Zalat St 10 Tuti Island 11 U of K $12120120 \mathrm{~km}$ Nrth of Khartoum)

\section{Aerosol samples}

The sampling instruments used in this study were a cyclone for near road-sides sampling and a dichotomous virtual impactor for the background air measurement (Carlsson 2000, Eltahir 2003).

The cyclone was placed with the sampling inlet approximately at $1.5 \mathrm{~m}$ above the ground level, and at one meter from the edge of the roadside. The flow rate was adjusted to $2.5 \mathrm{1} / \mathrm{min}$ to select particles of cut-off diameter similar in size to particles collected through the fine channels of the virtual impactor. Then it is possible to compare the road-side aerosols collected by the cyclone with the particulates collected from the general background air by the fine channel of the virtual impactor. Four samples were taken from each location. The sampling period for one sample was five hours. The study was usually carried out two times a day, during the morning and afternoon periods. The collection was conducted on roads with dense traffic, but away from industrial emissions.

The dichotomous virtual impactor was placed on the top of a building $3 \mathrm{~m}$ high. It separates the collection of air particulates of sizes $2.5 \mu \mathrm{m}$ by the fine channel and of sizes $10 \mu \mathrm{m}$ by the coarse one. Thus both fine particulates and coarse ones were collected on the filters. The filters in the 
impactor were changed every twelve hours during the day period.

The collection by the two instruments was performed using ring Teflon membrane filter (Millipore), $37 \mathrm{~mm}$ in diameter, with pore size $2 \mu \mathrm{m}$. The filter samples were then weighed and measured by EDXRF.

\section{Soil samples}

The soil samples were collected at the same locations as the air particulates. They were taken at distances of 1,5 and $10 \mathrm{~m}$ from the edge of both sides of the road, and at depths of $0.1,0.2$ and $0.3 \mathrm{~m}$. To calculate the enrichment factor (EF) for Khartoum aerosols relative to the north of Khartoum Sahara soil, 10 soil samples were collected from a location $120 \mathrm{~km}$ north of Khartoum.
All samples were then kept in air tight plastic bags for laboratory analysis. Two methods were used to prepare soil sample for EDXRF analysis. In the first method, each sample was poured and evenly distributed on a very thin and clean cellotape. The cello-tape was initially checked for contamination and was used only when free from any contaminants. In the second method, parts from the same samples were homogeneously mixed, dried by heating at $100^{\circ} \mathrm{C}$ for two hours, and then ground to powder form. Then they were pressed into pellet form of one inch diameter and about $1 \mathrm{~g}$ mass, using a pressing machine at 15 ton. The samples were then weighed and measured by EDXRF.

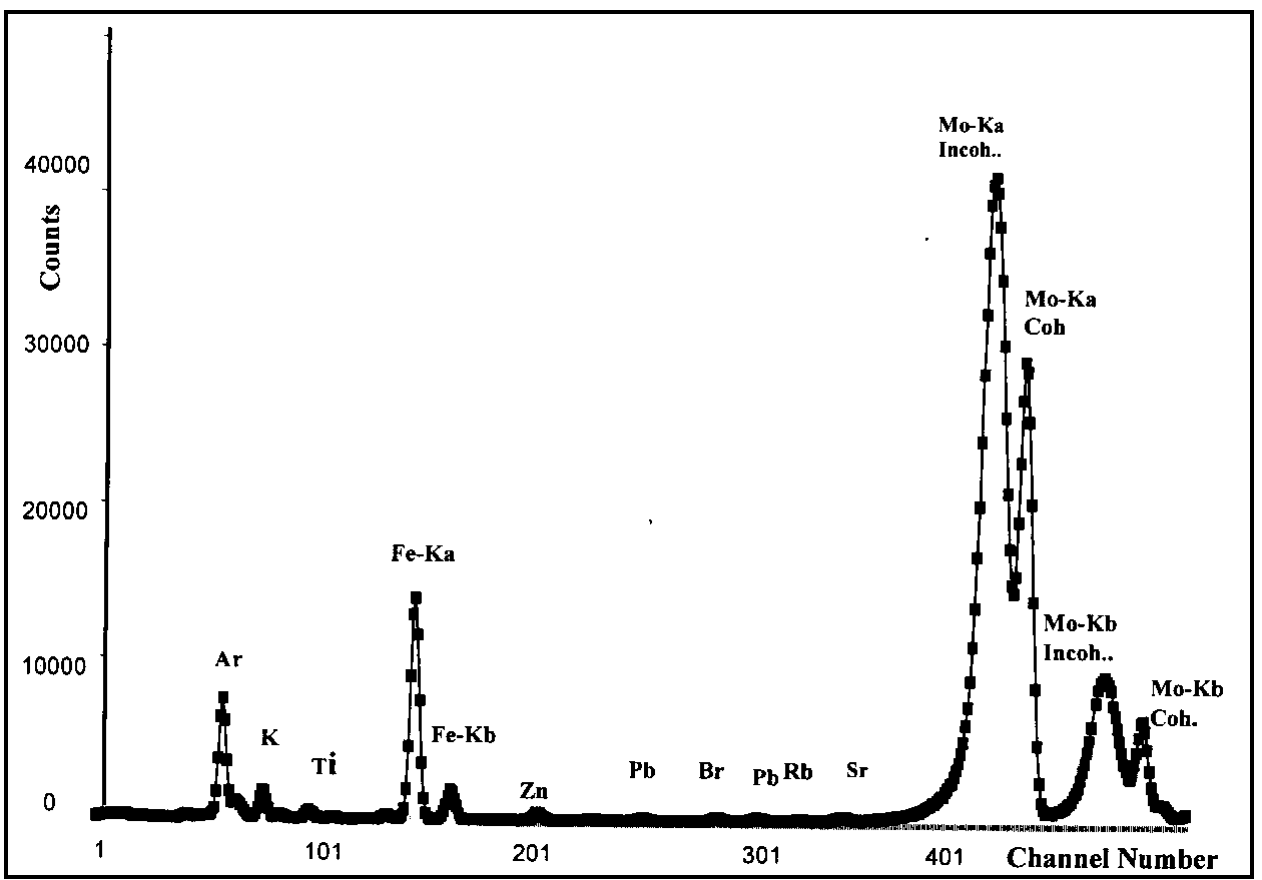

Figure 2: $\quad$ Typical spectrum from fine particulates of Khartoum background aerosols

\section{Analytical methods}

Use was made of two different spectrometer systems for the analysis of the samples. The aerosol samples and soil samples on cellotape were measured using a tube excitation
EDXRF spectrometer system described elsewhere (Standzenieks and Selin 1979, Eltahir 2003). The soil samples in pellet form were measured using Cd-109 EDXRF spectrometer system at the University of 
Khartoum, Sudan (Habbani and Salih 1999). Emphasis in the isotopic source method was on the determination of the elemental concentration of $\mathrm{Pb}$, while in the tube excitation method multi-element analysis was performed. The data from the measurements was analyzed using the computer program AXIL (Van Espen et al. 1986). Fig. 2 shows a typical spectrum of the fine particles in the background aerosols of Khartoum city. Details of the analysis procedure of the air particulates are described elsewhere (Eltahir et al. 2005). The data from the Cd-109 spectrometer system were converted to $\mathrm{Pb}$ concentrations using a calibration obtained by use of standard solutions of lead compounds.

\section{RESULTS AND DISCUSSION \\ Aerosol elemental concentrations}

The elemental range, mean concentration, the standard deviation (SD) and the median concentration of the background air particulates and near road-sides air particulates are presented in Table 1. The results of the elemental concentrations of the road-sides collections were obtained from computing an overall mean value out of the individual mean of the analytical results of the ten locations. The background elemental mean concentrations were obtained out of the analytical results of the impactor's fine channel. The high value of sample to sample $\mathrm{SD}$ is due to variations of the meteorological parameters e.g. wind and dust. Median concentration was presented in the Table because the outlier values have less effect on its value. In the Table some elements have been excluded because of being below detection limits in more than half of their analytical results e.g. $\mathrm{Cr}$ and $\mathrm{V}$.

It can be seen from the Table that all elemental concentrations in the road-sides airborne particulates have relatively higher levels than that of the background. These seem to reflect an influence of urban and natural sources on the road dust. Two distinct groups of elements could be characterized according to the difference in the level of the increase. The increment of the concentrations of the elements $\mathrm{K}, \mathrm{Ca}$, $\mathrm{Ti}, \mathrm{Mn}, \mathrm{Fe}$, and $\mathrm{Sr}$ (group1) is much less than of the elements $\mathrm{Ni}, \mathrm{Zn}$ and $\mathrm{Pb}$ (group2). However, in both groups the high levels of concentrations in the road-sides could be attributed to traffic emission.

Fig. 3 is a comparison between the mean elemental concentrations for some elements of the road-sides particulates and the fine particles of the background aerosols.

Table 1: Elemental range, mean (SD) and median concentrations of some elements in the background air and roadsides of down town Khartoum

\begin{tabular}{|c|c|c|c|c|c|c|}
\hline \multirow{2}{*}{ EI } & \multicolumn{2}{|c|}{ Min-Max (ng .m-3) } & \multicolumn{2}{|c|}{ Mean (SD) (ng .m-3) } & \multicolumn{2}{|c|}{ 'Median (ng .m-3) } \\
\hline & Background & Roadside & Roadside(SD) & Background (SD) & Roadside & Background \\
\hline $\mathrm{K}$ & $220-750$ & $830-1620$ & $1100(100)$ & $410(150)$ & 1100 & 340 \\
\hline $\mathrm{Ca}$ & $490-2600$ & $560-5800$ & $1800(650)$ & $1000(600)$ & 1300 & 810 \\
\hline $\mathrm{Ti}$ & $60-390$ & $80-380$ & $200(60)$ & $150(150)$ & 170 & 93 \\
\hline $\mathrm{V}$ & DL & $60-65$ & $60(10)$ & DL & 65 & DL \\
\hline Mn & $12-80$ & $40-100$ & $68(10)$ & $30(30)$ & 60 & 20 \\
\hline $\mathrm{Fe}$ & $600-3400$ & $420-5300$ & $2700(900)$ & $1400(1000)$ & 2500 & 915 \\
\hline $\mathrm{Ni}$ & $2-5$ & $50-120$ & $80(16)$ & $3(1)$ & 70 & 2 \\
\hline $\mathrm{Cu}$ & $1-4$ & DL & $200(30)$ & $13(6)$ & DL & 2 \\
\hline $\mathrm{Zn}$ & $8-25$ & $100-320$ & $15(1)$ & $4(2)$ & 190 & 11 \\
\hline $\mathrm{Br}$ & $2-8$ & $14-15$ & $15(1)$ & $4(3)$ & 15 & 3 \\
\hline $\mathrm{Sr}$ & $3-16$ & $14-30$ & $22(4)$ & $7(4)$ & 22 & 5 \\
\hline $\mathrm{Pb}$ & 4-11 & $30-90$ & $49(15)$ & $6(2)$ & 49 & 5 \\
\hline
\end{tabular}




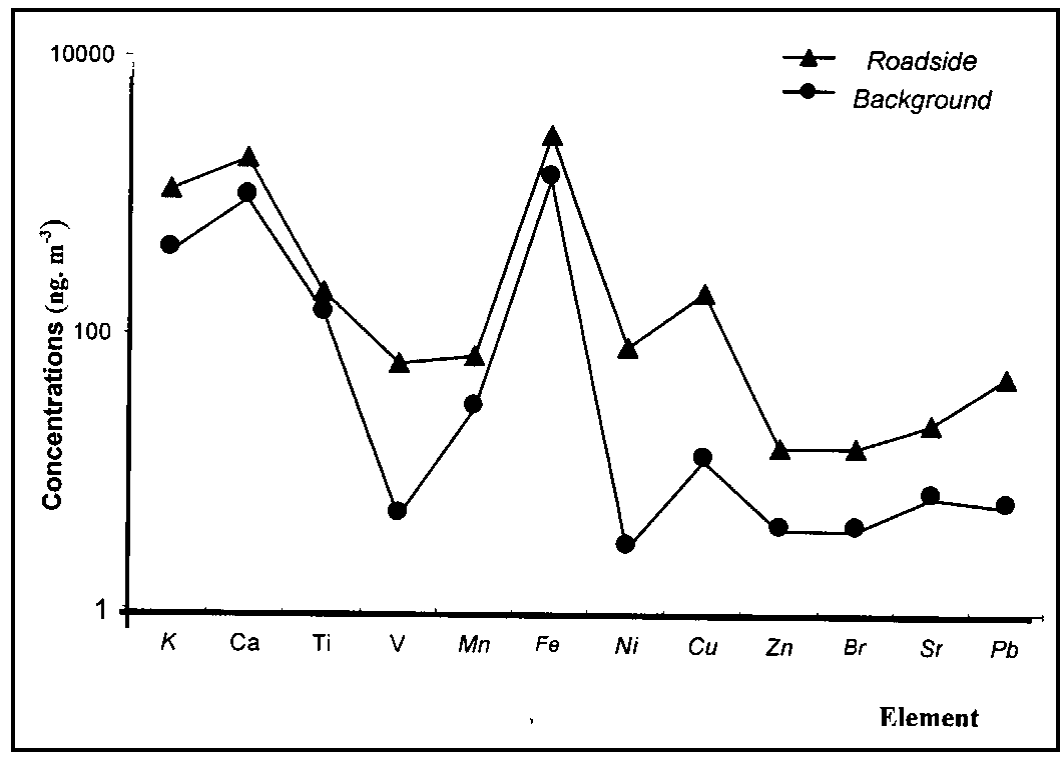

Figure 3: Elemental mean concentrations for some elements in background and near road-side aerosols in down town Khartoum

\section{Soil elemental concentrations}

The aim of the soil analysis was to study the correlation of some elements in the aerosols to their concentrations in the soil. The expected correlation was based on the assumption that the presence of the elements derived from the soil in an aerosol would be in the same proportion as in the soil. Near road-sides the traffic would have influence on both particulates concentrations and the soil.

Table 2 shows the enrichment factors for some elements in the background air and near road-sides of Khartoum relative to the southern belt of Sahara desert $120 \mathrm{~km}$ north of Khartoum. The concentrations of the continental crustal rock were obtained from Taylor and McLennan (1985), denoted as (T\&M) and from Rundick and Fountain (1995), denoted as (R\&F). Fig. 4 shows a comparison of the EFs for some elements in background aerosols and road-sides in down town Khartoum. The lead concentrations decreased with distance away from the road- sides. in the upper layer of the earth surface near road-sides They were found to be in the range $(10-50) \mu \mathrm{g} / \mathrm{g}$ in the upper layer of the earth surface near road-sides. Such concentration levels of $\mathrm{Pb}$ are in the normal range of $\mathrm{Pb}$ in the soil.

\section{Roadsides particulates}

The analytical results obtained from the soil samples from different locations near roadsides and from the southern Saharan belt, $120 \mathrm{~km}$ north of Khartoum, were used to calculate the EFs. The purpose was to examine the relationship between elemental concentrations in the soil and airborne concentrations. As can be seen from Table 2 the EFs for elements in group1 in the roadsides aerosols have values higher than the values obtained for group 2. Although the re-suspension of the soil raised the concentration levels of the two groups, the highly enriched elements $\mathrm{Ni}, \mathrm{Zn}$ and $\mathrm{Pb}$ in the road-sides are thought to have their origin from direct vehicles emission as well. It is known that $\mathrm{Pb}$ has been used as an anti- 
knock agent in automobile fuel. Ni could originate from oil combustion, while $\mathrm{Zn}$ compounds have been employed as anti- oxidants and as detergent/dispersant improvers for lubricating oils (Ogunsola et al. 1993).

Table 2: The EFs for some elements in background air and near roadsides of Khartoum, relative to north of Khartoum Sahara desert soil and to the continental crust. $\left({ }^{*} \mathrm{NA}=\right.$ not available: either in the reference crust results or not detected in the present work)

\begin{tabular}{ccccccc}
\hline & \multicolumn{2}{c}{ EF (Crust/ R\&F) } & \multicolumn{2}{c}{ EF (Crust/ T\&M) } & \multicolumn{2}{c}{ EF (Sahara desert) } \\
\hline \multirow{2}{*}{ Element } & $\begin{array}{c}\text { Back- } \\
\text { ground air }\end{array}$ & Road-side & $\begin{array}{c}\text { Back- } \\
\text { ground air }\end{array}$ & Road-side & $\begin{array}{c}\text { Back- } \\
\text { ground air }\end{array}$ & Road-side \\
\hline $\mathrm{Si}$ & 0.66 & 0.49 & 0.87 & 0.66 & NA* $^{*}$ & NA \\
$\mathrm{K}$ & 1.7 & 3.4 & 3.2 & 6.5 & 2.5 & 5.1 \\
$\mathrm{Ca}$ & 0.61 & 0.83 & 0.68 & 0.92 & 3.2 & 4.3 \\
$\mathrm{~V}$ & $\mathrm{NA}$ & 9.0 & $\mathrm{NA}$ & 7.6 & $\mathrm{NA}$ & $\mathrm{NA}$ \\
$\mathrm{Cr}$ & 0.94 & $\mathrm{NA}$ & 0.78 & $\mathrm{NA}$ & $\mathrm{NA}$ & $\mathrm{NA}$ \\
$\mathrm{Mn}$ & 1.1 & 1.8 & 0.77 & 1.3 & 1.7 & 2.9 \\
$\mathrm{Fe}$ & 0.76 & 1.1 & 0.71 & 1.0 & 3.0 & 4.3 \\
$\mathrm{Ni}$ & 1.7 & 33 & 1.0 & 21 & 3.6 & 71 \\
$\mathrm{Cu}$ & 2.3 & $\mathrm{NA}$ & 0.96 & $\mathrm{NA}$ & 2.3 & NA \\
$\mathrm{Zn}$ & 5.0 & 57 & 5.6 & 67 & 3.6 & 43 \\
$\mathrm{Rb}$ & 0.48 & $\mathrm{NA}$ & 1.1 & $\mathrm{NA}$ & 0.4 & NA \\
$\mathrm{Sr}$ & 0.60 & 1.4 & 0.97 & 2.3 & 1.7 & 4.1 \\
$\mathrm{~Pb}$ & 13 & 81 & 27 & 165 & 8.8 & 54 \\
\hline
\end{tabular}

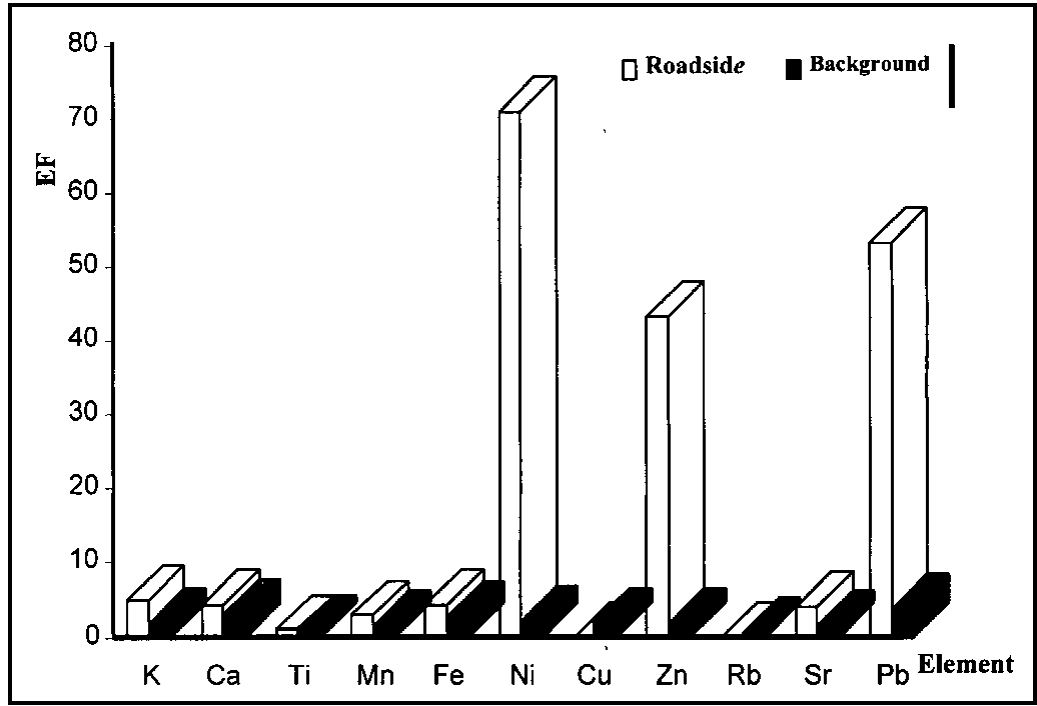

Figure 4: Comparison of the EFs for some elements in road-sides and background aerosols of down town Khartoum

Lead attributed to traffic

Historically lead has been the most reliable tracer of traffic. To investigate the source of road-sides lead, the bromine-to-lead ratio 
was calculated. In the proximity of roadsides, for the aerosols derived from direct car exhaust, the same ratio between $\mathrm{Br}$ and $\mathrm{Pb}$ was found as for the anti-knock agent of the fuel. This ratio was used to trace out vehicular lead concentrations in the atmosphere (O'Conner et al. 1977). Table 3 shows a comparison of $\mathrm{Pb} / \mathrm{Br}$ ratio for Khartoum with some other countries (Faiq and Abdalla 1988, Ogunsola 1993, Bennet et al. 2005, Moloi et al. 2002). Although small differences occur, there is generally a good agreement between the values for the different countries. Figure 5 shows a good correlation between $\mathrm{Pb}$ and $\mathrm{Br}$ in Khartoum aerosols This strengthens the suggestion of their origin from automobile emissions.

Table 3. Comparison of $\mathrm{Pb} / \mathrm{Br}$ ratio in Khartoum with other countries in the region

\begin{tabular}{lc}
\hline Country & $\mathbf{P b} / \mathbf{B r}$ \\
\hline Khartoum (Background, atmospheric) & 2.43 \\
Khartoum (Road side, atmospheric) & 3.3 \\
Lagos (Nigeria, atmospheric) & 2.24 \\
Iraq (atmospheric) & 2.43 \\
Dar Es-Salaam (Tanzania, atmospheric.) & 2.7 \\
Gaborone (Botswana, atmospheric) & 2.0 \\
\hline
\end{tabular}

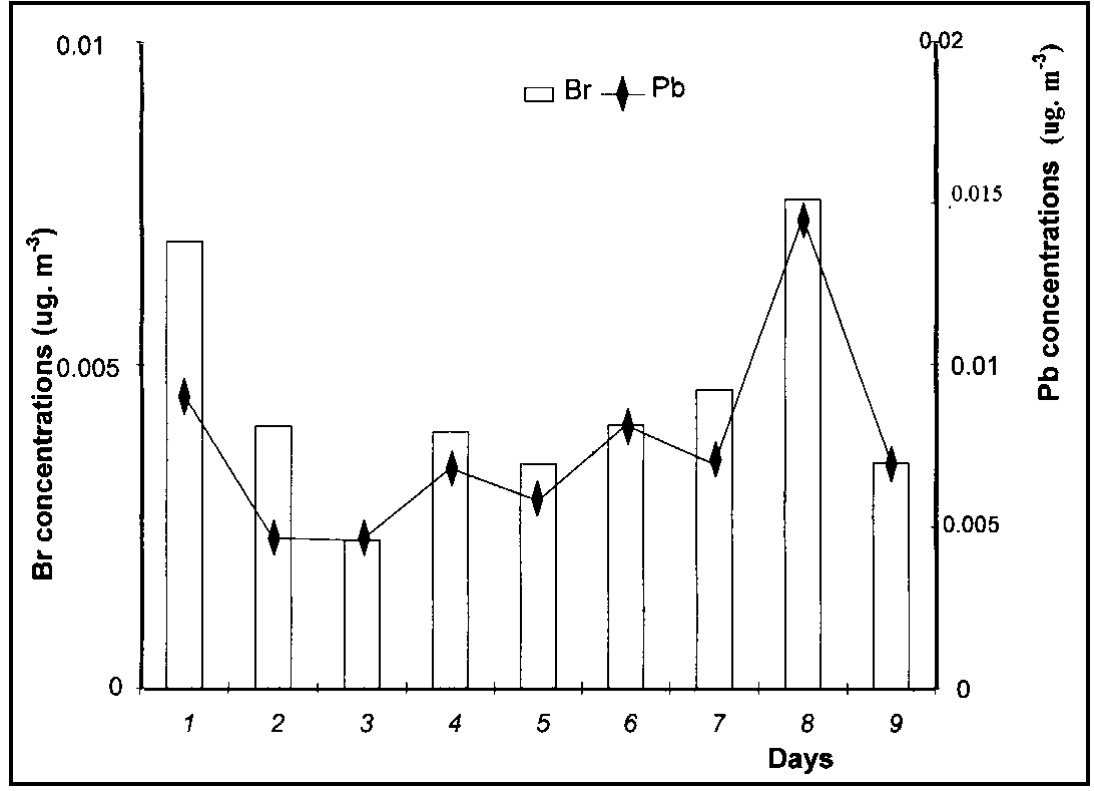

Figure 5: $\quad$ Concentration profiles of $\mathrm{Pb}$ and $\mathrm{Br}$ in Khartoum aerosols

\section{CONCLUSION}

The analytical and the statistical results from this study indicated elevated concentrations levels for some elements near road-sides compared to the background values as expected. The influence of traffic to the street dust in Khartoum city is characterized by elevated levels of the elements $\mathrm{Zn}$, Ni and $\mathrm{Pb}$, which have been highly enriched near roadsides. Their enhancement appears to originate from the mobilization and resuspension of the surface soil near roads and from direct automobile emissions. 
The $\mathrm{Pb} / \mathrm{Br}$ ratio in Khartoum atmospheric particulates is in good agreement with ratios obtained from some other countries in the region. The strong correlation observed between $\mathrm{Pb}$ and $\mathrm{Br}$ indicated that the roadsides lead source is automobile emissions.

The study revealed that the concentrations of the soil lead $(10-50 \mu \mathrm{g} / \mathrm{g})$ are of little health concern because they were less than the prescribed ambient air quality standards.

\section{ACKNOWLEDGEMENTS}

One of the authors, Eltahir, wishes to express his gratitude for the financial support from the Forensic Laboratory, Sudan and from SIDA, Sweden. The access to the equipment at Chalmers University of Technology and the University of Khartoum is acknowledged.

\section{REFERENCES}

Bennet C, Jonsson P and Selin EL 2005 Concentrations and sources of trace elements in particulate air pollution, Dar Es-Salaam, studied by EDXRF technique. X-Ray Spectrometry 34: 1-6.

Carlsson Cecilia 2000 Investigations of a plastic cyclone and comparison with a dichotomous impactor for aerosol particles measurement in urban background air. MSc thesis, Chalmers University of Technology, Sweden.

Chimidza S, Viksna A and Selin EL 2001 EDXRF and TXRF analysis of aerosol particles and the mobile fraction of soil in Botswana. X-Ray Spectrometry 30: 301-307.

Djupstrom FM 1995 Trace elements in airborne particles as observed at remote locations. $\mathrm{PhD}$ thesis, Chalmers University of Technology and Gothenburg University, Sweden.

Eltahir EM 2003 EDXRF elemental profiles and characterization of size-segregated particulate matter of aerosols in Khartoum area. $\mathrm{Ph} \mathrm{D}$ thesis, University of Khartoum, Sudan.

Eltahir EM, Selin EL and Habbani FI 2005
Elemental characterization of airborne particles in Khartoum, Sudan. X-Ray Spectrometry 34: 144-152.

Eltayeb MAH 1993 Application of x-ray emission spectrometry to some environmental problems in Africa. $\mathrm{PhD}$ thesis, University of Antwerp, Belgium.

Faiq SY and Abdalla F 1988 Water, air and soil pollution. Iraq Council for Research, 42-153.

Habbani FI and Salih SE 1999 Status of heavy metals pollution in the Nile around Khartoum area. Tanz. J. Sci. 25: 17-37.

Hassan GGA 1984 Investigations of lead pollution from automobile emissions in Khartoum. M Sc thesis, University of Khartoum, Sudan.

Hassuna RK, Eltayeb MAH and Idris AA 1998 Study of atmospheric aerosols in Khartoum using $\mathrm{x}$-ray fluorescence analysis. In: Proc. $4^{\text {th }}$ Conf. on the Peaceful Uses of Atomic Energy, AAEA, Tunis.

Hinds WC 1982 Aerosol technology: properties, behaviour and measurement of airborne particles. John Wiley.

McLellan RO 2002 Setting ambient air quality standards for particulate matter. Toxicology 181-182: 329-347.

Moloi K, Viksna A, Selin EL and Standzenieks P 2002 Sequential leaching of trace elements in fine particle aerosols samples on teflon filters. X-Ray Spectrometry 31: 27-34.

O'Connor BH, Kerrigan GC, Thomas WW and Pearce AT 1977 Use of bromine levels in airborne particulate samples to infer vehicular lead concentrations in the atmosphere. Atmos. Environ. 11: 635638.

Ogunsola OJ, Oluwole AF, Obioh IB, Akeredolu FA, Akanle OA and Spyrou NM 1993 Analysis of suspended air particulates along some motorways in Nigeria by PIXE and EDXRF. Nucl. Instr. and Meth. in Phys. Res. B79: 404-407.

Rundick RL and Fountain DM 1995 Nature and composition of the continental crust. 
Reviews in Geophys. 33: 267-309.

Standzenieks P and Selin Eva 1979

Background reduction of $x$-ray

fluorescence spectra in a secondary target energy dispersive spectrometer. $\mathrm{Nucl}$. Instrum. and Methods 165: 63-65.

Taylor SR and McLennan SM 1985 The continental crust: its composition and evolution. Blackwell Scientific
Publications, Geoscience.

Van Espen P, Janssens K and Nobels J 1986 Axil-PC software for the analysis of complex x-ray spectra. University of Antwerp (U.I.A), Belgium.

Wahlin P, Palmgren F and Van Dingenen RO 2001 Experimental studies of ultrafine particles in streets and relationship to traffic. Atmos. Environ. 35: 63-69. 